\title{
Avaliação das Propriedades Reológicas de Blendas de PEAD Virgem/PEAD Reciclado
}

\author{
Sandra A. Cruz \\ Centro de Engenharia, Modelagem e Ciências Sociais Aplicadas, UFABC \\ Marcelo Farah \\ Braskem S.A., RS \\ Maria Zanin, Rosario E. S. Bretas \\ Departamento de Engenharia de Materiais, UFSCar
}

\begin{abstract}
Resumo: Neste trabalho, as propriedades reológicas de blendas de PEAD virgem e PEAD reciclado, em diferentes porcentagens, foram avaliadas em regime permanente, transiente e dinâmico de cisalhamento utilizando-se reometria cone-placa e reometria capilar. Embalagens de PEAD pós-consumo foram coletadas e submetidas aos processos básicos de recuperação de plásticos: lavagem, moagem e secagem. Formulações, previamente estabilizadas, contendo 0, 25, 50, 75 e $100 \%$ de material reciclado, adicionado à resina virgem, foram reprocessadas por extrusão e posterior injeção. Das medidas das propriedades reológicas foi possível concluir que a incorporação de material reciclado proveniente de resíduo pós-consumo à resina virgem promove, neste caso, uma diminuição da massa molar e aumento na sua distribuição. Além disso, um estudo das propriedades reológicas permite a predição de seu comportamento frente ao processamento de resinas recicladas pós-consumo.
\end{abstract}

Palavras-chave: Reciclagem, resíduos pós-consumo, PEAD, propriedades reológicas.

\section{Evaluation of Rheological Properties of Virgin HDPE/Recycled HDPE Blends}

Abstract: In this study, the incorporation of a high density polyethylene (HDPE) resin in a virgin resin was assessed by means of its rheological properties with the use of shear steady, transient and dynamic flows using cone and plate and capillary rheometry. HDPE post-consumer packaging was collected and submitted to a basic process of plastic recovering: washing, grinding, and drying. The formulations had 0, 25, 50, 75 and $100 \%$ of recycled material added to the virgin resin, and were reprocessed by extrusion and injection molding with stabilization. From the rheological measurements it was concluded that the incorporation of the recycled material from post-consumer packaging to the virgin resin produced, in this case, a decrease in the molar mass and an increase in its distribution. Therefore, the rheological properties allow the prediction of the processing behavior of post-consumer recycled materials.

Keywords: Recycling, post-consumer, HDPE, rheological properties.

\section{Introdução}

As crescentes aplicações do polietileno de alta densidade (PEAD), principalmente no setor de embalagens de rápido descarte, vêm tornando-o um dos plásticos mais consumidos no mercado mundial. Estudos realizados sobre a composição dos resíduos sólidos urbanos no Brasil, indicaram que o PEAD encontra-se em aproximadamente $30 \%$ do total dos plásticos rígidos coletados, perdendo o primeiro lugar apenas para o poli (tereftalato de etileno), PET, com $60 \%{ }^{[1]}$.

Apesar do plástico ter conquistado aos poucos seu espaço como material de grande importância para a sociedade, atualmente seu descarte é um problema para o mundo e principalmente para o Brasil. A falta de gerenciamento adequado para os resíduos urbanos, pode resultar em descartes impróprios, e tem contribuído para entupimentos da rede de esgoto e para a formação de enchentes, propiciando a proliferação de vetores e gerando graves problemas ambientais, como por exemplo, poluição de rios e nascentes e mesmo em aterros sanitários, o chorume que se forma causa a contaminação de aquiúferos e lençóis freáticos. Aliado a isto, a baixíssima degradabilidade dos mesmos e o seu elevado volume fazem com que os rejeitos plásticos ocupem vastos espaços por tempo muito longo, diminuindo o tempo de vida útil dos aterros sanitários. Sendo assim, o estudo do resíduo sólido urbano, de seus componentes e da viabilidade técnica e econômica da sua reciclagem é de fundamental importância no contexto da sociedade contemporânea ${ }^{[2,3,4]}$. Apesar do PEAD estar sendo amplamente utilizado em aplicações como pavimentação (reciclado misturado com asfalto), madeira plástica, construção civil (eletrodutos, conduítes, etc.),

Autor para correspondência: Sandra A. Cruz, Centro de Engenharia, Modelagem e Ciências Sociais Aplicadas, Universidade Federal do ABC (UFABC), CEP: 09090-400, Santo André, SP, Brasil.E-mail: sandra.cruz@ufabc.edu.br 
plasticultura (lonas), embalagens flexíveis, indústria automobilística, entre outros, poucos esforços têm sido realizados no sentido de analisar suas propriedades reológicas.

O comportamento de fluxo de materiais poliméricos no estado fundido, em geral, pode ser descrito pela Lei das Potências, na forma ${ }^{[5,6]}$ :

$$
\tau=\kappa(\dot{\gamma})^{\mathrm{n}}
$$

onde $\tau$ e $\dot{\gamma}$ são a tensão e a taxa de cisalhamento, respectivamente, $\kappa$ é a consistência do material e $n$ é o índice de potência. Quando $n=1$, diz-se que o material apresenta comportamento Newtoniano, enquanto que quando $n>1$ tem-se o comportamento dilatante e $\mathrm{n}<1$, pseudoplástico. Os materiais poliméricos enquadram-se geralmente nesta última categoria.

A elevada massa molar, a distribuição de tamanho das macromoléculas, o grande número de conformações estruturais, bem como a possibilidade de emaranhamentos temporários das cadeias poliméricas, são responsáveis pelas grandes diferenças de fluxo e, portanto refletem-se diretamente no seu processamento, ou no caso de materiais reciclados, no seu reprocessamento.

As propriedades de fluxo de fluidos viscoelásticos são dependentes da temperatura, da taxa de deformação e do tempo de observação. Dentre as propriedades reológicas, a viscosidade é um dos parâmetros mais utilizados no estudo do comportamento dos materiais poliméricos durante o processamento, uma vez que, a maioria dos processos de transformação ocorre em fluxos cisalhantes. Medidas de módulos de armazenamento $\left(G^{\prime}\right)$ e de perda $\left(G^{\prime \prime}\right)$ em cisalhamento, que estão relacionados com a energia armazenada e energia dissipada durante um ciclo, respectivamente, também são muito utilizadas no estudo de processamento de polímeros. O módulo de armazenamento é dependente da rigidez das macromoléculas e do seu emaranhamento, enquanto que o módulo de perda é dependente das ligações que controlam as mudanças conformacionais dos segmentos das cadeias, e do deslocamento de uma cadeia com relação à outra. O comportamento elástico e viscoso destes materiais pode ser alterado pela taxa de aplicação de tensão ou deformação e a temperatura do ensaio ${ }^{[5,7]}$.

$\mathrm{O}$ estudo da dependência da viscosidade com a temperatura ajuda a esclarecer o mecanismo do processo de fluxo, a elucidar a relação estrutural dos polímeros e seu comportamento sob deformações além de ter um substancial efeito na processabilidade do material visto que é a sensibilidade da viscosidade com a mudança de temperatura que governa a escolha das condições de processamento ${ }^{[6]}$.

Ainda, análises de propriedades reológicas sob elevadas taxas de cisalhamento, realizadas em reometria capilar, permitem estudar o comportamento reológico do polímero fundido em situação similar à encontrada durante processos de extrusão e injeção, permitindo, por exemplo, definir o tipo e as condições de processamento ao qual o material pode ser submetido. Já a análise das propriedades reológicas sob baixas taxas de cisalhamento, realizada em reometria rotacional, permite determinar o módulo de perda e de armazenamento, verificar a existência ou não de miscibilidade em sistemas poliméricos no estado fundido, entre outras propriedades ${ }^{[8,9]}$.

Assim, este trabalho teve como objetivo principal estudar a influência da incorporação de material reciclado pós-consumo ao PEAD virgem, em diversas porcentagens, quanto as suas propriedades reológicas em regime permanente (viscosidade em baixas taxas de cisalhamento), transiente (crescimento e relaxações de tensões e deformação) e dinâmico (viscosidade e módulo complexo), em três temperaturas distintas.

\section{Materiais e Métodos}

\section{Materiais}

O PEAD virgem utilizado, GM 9450F, fornecido pela Ipiranga Petroquímica S.A., apresenta índice de fluidez 0,32 g/10 min (norma ASTM D 1238) e densidade de $0,952 \mathrm{~g} / \mathrm{cm}^{3}$. É encontrado na forma de grânulos com préestabilização básica para processamento. O material reciclado utilizado foi o PEAD, coletado junto ao sistema de coleta seletiva existente na Universidade Federal de São Carlos/UFSCar, e foi constituído, predominantemente, de produtos de higiene pessoal e limpeza. Para a estabilização durante o reprocessamento do material recuperado foi utilizada uma mistura comercial do antioxidante Irganox B215 (2:1 Irgafos 168: Irganos 1010) fornecido pela Ciba Especialidades Químicas Ltda - Brasil.

\section{Condições de recuperação e incorporação de $P E A D$ reciclado}

O PEAD coletado passou pelo processo básico de recuperação de plástico pós-consumo: moagem (moinho de facas Primotécnica, 738 rpm e 4 HP - flocos de 0,3 in), lavagem (em lavadora desenvolvida no 3R-Núcleo de Reciclagem de Resíduos $^{[10]}$ com água pura por 5 minutos e com solução de soda cáustica a $1 \%$ por mais 5 minutos, sendo o enxágüe realizado com água por 10 minutos na própria lavadora) e secagem (em estufa com renovação e circulação de ar MA 037 por 24 horas a $50{ }^{\circ} \mathrm{C}$ ).

O material recuperado foi reprocessado pelo processo de extrusão (Gerst tipo $25 \mathrm{X} 24 \mathrm{D}, \mathrm{L} / \mathrm{D}=24$, perfil de temperatura de $150,180,180{ }^{\circ} \mathrm{C}$ e velocidade da rosca de 70-80 rpm) com adição de 0,2\% em peso do antioxidante Irganox B215. Posteriormente, este material foi incorporado à resina virgem nas proporções 25, 50 e 75\%, e injetado (Arburg $270 \mathrm{~V}$ com perfil de temperatura de 160, 180, 180 e $190{ }^{\circ} \mathrm{C}$ e temperatura do molde de $50{ }^{\circ} \mathrm{C}$ ). A Tabela 1 apresenta a nomenclatura utilizada no trabalho referente às formulações desenvolvidas, bem como as concentrações de PEAD virgem e reciclado. 
Tabela 1. Nomenclatura e concentrações (\% em peso) para as formulações desenvolvidas de PEAD.

\begin{tabular}{lcc}
\hline Formulação & $\begin{array}{c}\text { Resina } \\
\text { virgem }(\%)\end{array}$ & $\begin{array}{c}\text { Resina } \\
\text { reciclada* }(\%)\end{array}$ \\
\hline R-0\% & 100 & 0 \\
R-25\% & 75 & 25 \\
R-50\% & 50 & 50 \\
R-75\% & 25 & 75 \\
R-100\% & 0 & 100 \\
\hline
\end{tabular}

*todas as formulações contêm $0,2 \%$ em massa de antioxidante.

\section{Caracterização reológica}

As amostras utilizadas para a caracterização reológica a baixas taxas/frequiências de cisalhamento de todas as formulações foram placas injetadas; sendo que para a reometria capilar foi utilizado material na forma de grãos. Todos os ensaios foram realizados em duplicata para aumentar a confiabilidade dos mesmos e realizados nas temperaturas de 190,210 e $230{ }^{\circ} \mathrm{C}$.

\section{Regime permanente}

As viscosidades em regime permanente de cisalhamento foram determinadas em um reômetro Rheometrics ARES com taxa de $0,1 \mathrm{a} 100 \mathrm{~s}^{-1}$. A geometria utilizada foi de placas paralelas, sendo o diâmetro das placas de $25 \mathrm{~mm}$ e distância entre elas de $1 \mathrm{~mm}$.

\section{Regime transiente}

As medidas de crescimento e relaxação de tensões foram realizadas no reômetro Rheometrics ARES a taxas de 0,5; 1,5 e 2,5 rad/s sendo a amostra cisalhada por 100 segundos e relaxada por 150 segundos. O ensaio de fluência foi realizado no equipamento Rheometrics SR 200 sendo aplicada uma tensão de $1000 \mathrm{~Pa}$ por 400 segundos e medida a recuperação elástica por mais 400 segundos. A geometria utilizada foi de placas paralelas, sendo o diâmetro de $25 \mathrm{~mm}$ e distância entre as placas de $1 \mathrm{~mm}$.

\section{Regime dinâmico}

A fim de verificar alterações moleculares que poderiam ocorrer com o reprocessamento utilizou-se a reometria de cone placa num reometro Rheometrics SR 200, a temperatura de $190^{\circ} \mathrm{C}$, em atmosfera inerte de nitrogênio. A dimensão da placa inferior e superior na forma de cone foi de $25 \mathrm{~mm}$, sendo esta última com 0,1 rad de ângulo, e velocidade angular de 0,1 a $500 \mathrm{rad} / \mathrm{s}$. Determinou-se a partir dos resultados a viscosidade complexa em função da freqüência e do tempo $\eta *(\omega, \mathrm{t})$, o módulo de armazenamento em cisalhamento $\mathrm{G}^{\prime}(\omega)$ e o módulo de perda em cisalhamento G"' $(\omega)$ em função da frequiência. $\mathrm{O}$ deslocamento do ponto de cruzamento quando $\mathrm{G}^{\prime}(\omega)$ coincide com G” $(\omega)$ permite predizer se está ocorrendo aumento ou diminuição de massa molar (MM), bem como alargamento ou estreitamento da distribuição de massa molar (DMM) conforme mostra a Figura $1^{[11]}$.

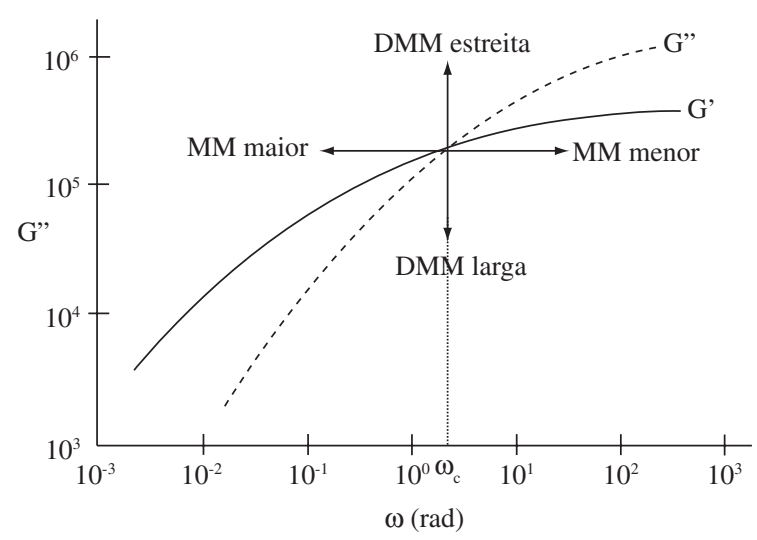

Figura 1. Curvas de G' e G" para um dado polímero, indicando como a freqüência $(\omega)$ se desloca com a variação de massa molar $(\mathrm{MM})$ e a distribuição de massa molar (DMM) ${ }^{[10]}$.

\section{Reometria capilar}

Os experimentos de reometria capilar foram realizados em um reômetro Capilar Instron 3211, sendo as amostras na forma de grãos. A temperatura utilizada foi de 190, 210 e $230{ }^{\circ} \mathrm{C}$ com velocidade de descida do pistão de $1,5,10,50$, $100,200,300$ e $350 \mathrm{~mm} / \mathrm{min}$ e razão L/D = 20. Utilizou-se a correção de Rabinowitsch para ajustar o desvio do comportamento Newtoniano. Isto porque, quando experimentos em reômetros capilares utilizando fluidos não-Newtonianos são realizados, a taxa de cisalhamento na parede pode ser expressa segundo a equação de Rabinowitsch:

$$
\dot{\gamma}_{w}=\left(\frac{4 Q}{\pi R_{c}^{3}}\right)\left(\frac{3+b}{4}\right)
$$

O termo $(3+b) / 4$ representa a correção de Rabinowitsch, e quando o fluido analisado não segue a Lei das Potências, a correção deve ser realizada para a determinação da taxa de cisalhamento verdadeira na parede ${ }^{[10]}$.

\section{Resultados e Discussão}

\section{Regime permanente}

A Figura 2 apresenta os resultados de viscosidade a baixas taxas de cisalhamento para as formulações contendo 0 , $25,50,75$ e $100 \%$ de material reciclado incorporado à resina virgem nas temperaturas de 190,210 e $230{ }^{\circ} \mathrm{C}$.

Analisando os resultados da Figura 2, pode-se observar que todas as curvas apresentam uma redução na viscosidade em função da taxa de cisalhamento dentro da faixa analisada, não apresentando um platô Newtoniano (viscosidade constante). Como a viscosidade é função da estrutura molecular, em uma primeira análise as amostras seguem a regra da aditividade, indicando que a redução na massa molar do polímero ocorreu devido a um aumento na incorporação de material reciclado.

Com o aumento de temperatura, uma ligeira diminuição nos valores de viscosidade, principalmente em regiões 
de baixas taxas pode ser observado. Em altas temperaturas ocorre uma redução na intensidade da interação intermolecular devido à vibração das cadeias poliméricas, aumentando o volume livre, reduzindo desta forma o atrito entre as mesmas e portanto a viscosidade ${ }^{[12]}$.

\section{Regime transiente}

As mudanças conformacionais que podem ocorrer em uma cadeia polimérica requerem um tempo maior do que sua
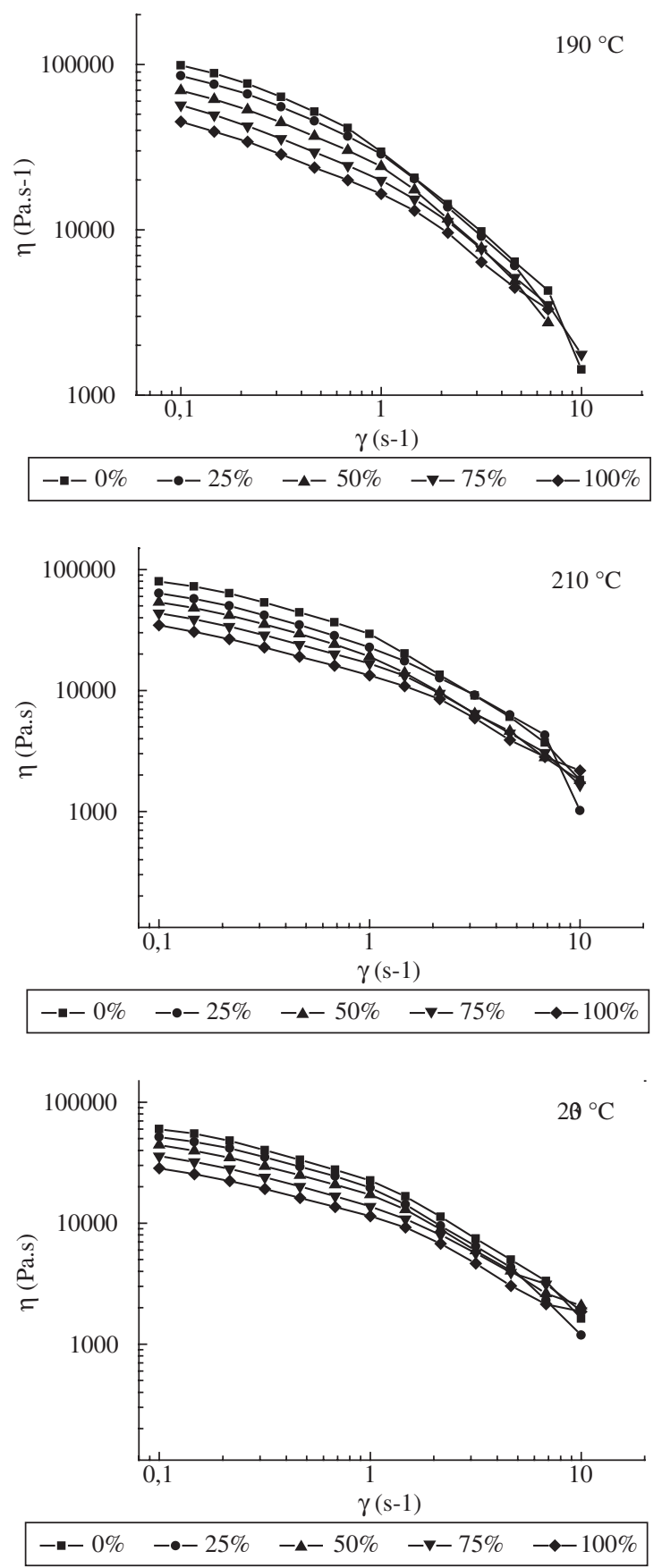

Figura 2. Viscosidade a baixas taxas de cisalhamento para as formulações R-0\%, R-25\%, R-50\%, R-75\% e R-100\% à temperatura de 190 , 210 e $230{ }^{\circ} \mathrm{C}$ resposta viscoelástica. Assim, para estudar o crescimento de tensões, as amostras foram cisalhadas a diferentes taxas de cisalhamento durante 100 segundos; após este intervalo de tempo, o cisalhamento foi subitamente interrompido e a relaxação das tensões foi medida durante 150 segundos, como mostra a Figura 3. As medidas foram realizadas às temperaturas de 190, 210 e $230^{\circ} \mathrm{C}$ com taxas de cisalhamento de $0,5,1,5$ e $2,5 \mathrm{~s}^{-1}$.

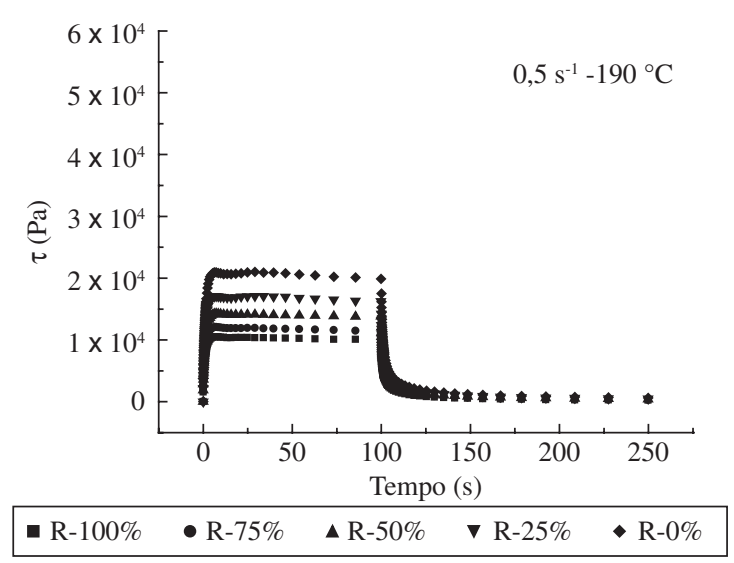

(a)

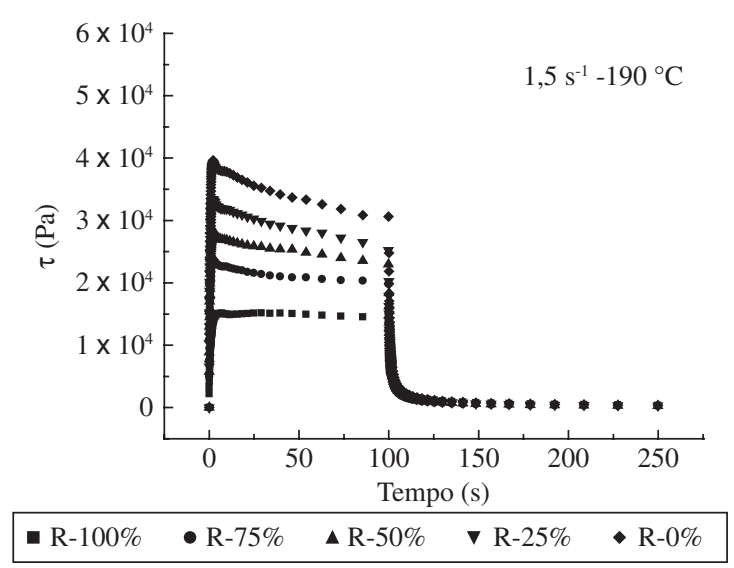

(b)

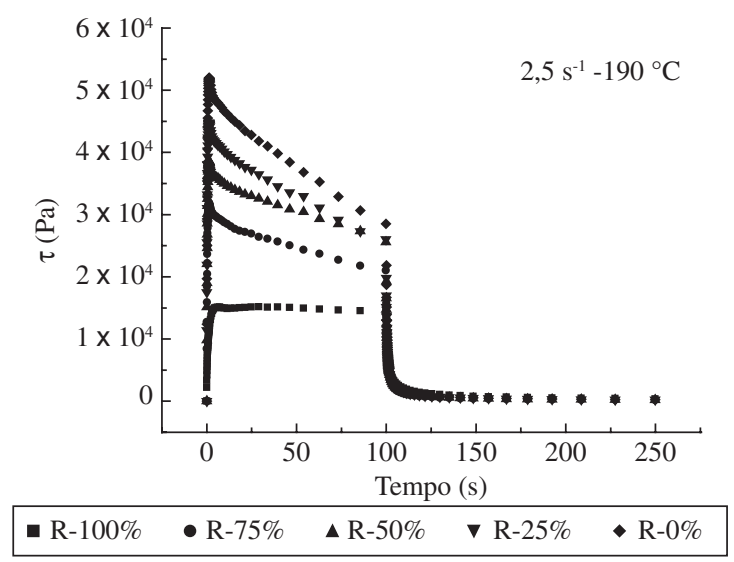

(c)

Figura 3. Crescimento de tensões e relaxação de tensões para as formulações R-0\%, R-25\%, R-50\%, R-75\% e R-100\% a $190{ }^{\circ} \mathrm{C}$ com diferentes taxas de cisalhamento: a) $0,5 \mathrm{~s}^{-1}$; b) $1,5 \mathrm{~s}^{-1}$; e c) $2,5 \mathrm{~s}^{-1}$. 
Pode-se observar que o pico máximo de tensão ("stress overshoot"), aumenta com o aumento do cisalhamento imposto, como esperado, e se torna mais intenso para a resina virgem e para aquelas com menor porcentagem de material reciclado. Para o PEAD 100\% reciclado é observado o mesmo comportamento independente da taxa de cisalhamento aplicada, ou seja, o PEAD $100 \%$ reciclado acumula menos tensões durante o cisalhamento do que a resina pura. Este comportamento indica um menor número de emaranhamentos, e portanto, menor massa molar e maior distribuição de massa molar quando comparado com a resina virgem.



(a)

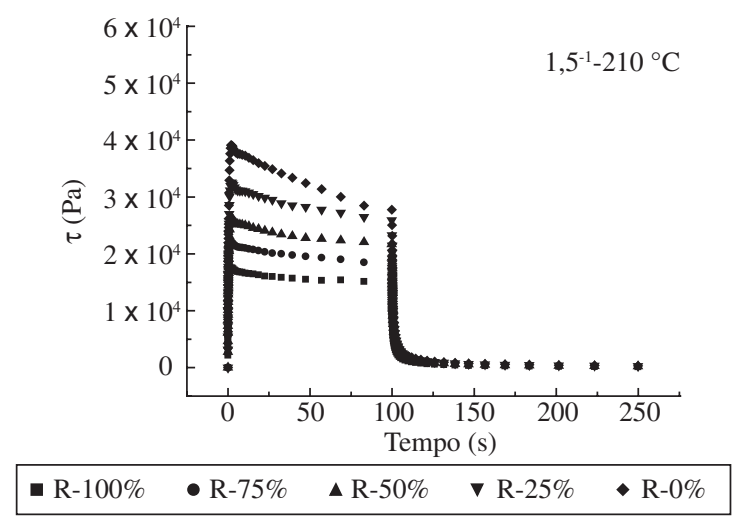

(b)



(c)

Figura 4. Crescimento de tensões e relaxação de tensões para as formulações R-0\%, R-25\%, R-50\%, R-75\% e R-100\% a $210{ }^{\circ} \mathrm{C}$ com diferentes taxas de cisalhamento: a) $0,5 \mathrm{~s}^{-1}$; b) $1,5 \mathrm{~s}^{-1}$; e c) $2,5 \mathrm{~s}^{-1}$.
Observa-se também, que as amostras com menor porcentagem de material reciclado demandam um tempo superior para atingir o regime permanente, principalmente em taxas maiores como 1,5 e $2,5 \mathrm{~s}^{-1}$. Isto ocorre devido a maior massa molar e ao maior número de emaranhamentos.

As Figuras 4 e 5 apresentam os mesmos resultados obtidos nas Figura 3, porém nas temperaturas de 210 e $230{ }^{\circ} \mathrm{C}$, respectivamente. Observa-se, o mesmo comportamento, independente da temperatura.

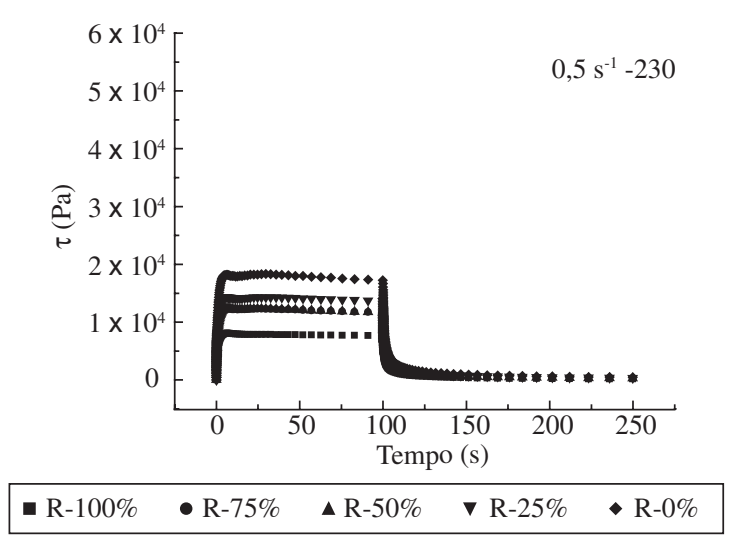

(a)



(b)



(c)

Figura 5. Crescimento de tensões e relaxação de tensões para as formulações R-0\%, R-25\%, R-50\%, R-75\% e R-100\% a $230{ }^{\circ} \mathrm{C}$ com diferentes taxas de cisalhamento: a) $0,5 \mathrm{~s}^{-1}$; b) $1,5 \mathrm{~s}^{-1}$; e c) $2,5 \mathrm{~s}^{-1}$. 


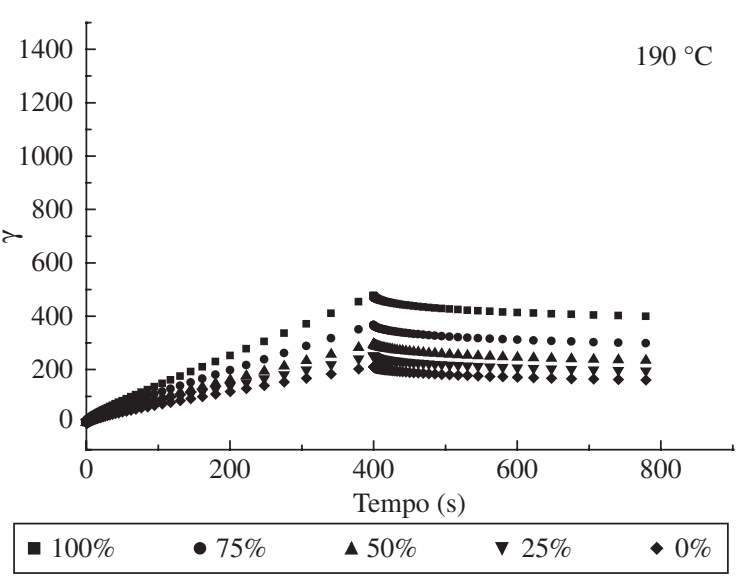

(a)



(b)

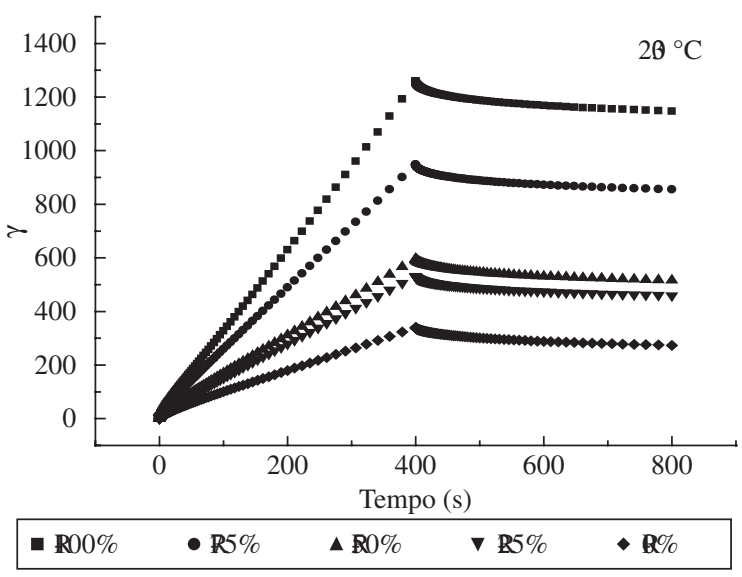

(c)

Figura 6. Resultados de deformação em função do tempo para as formulações R-0\%, R-25\%, R-50\%, R-75\% e R-100\% em diferentes temperaturas: a) $190{ }^{\circ} \mathrm{C}$; b) $210^{\circ} \mathrm{C}$; e c) $230^{\circ} \mathrm{C}$.

A Figura 6 apresenta os resultados de deformação em função do tempo para as formulações contendo $0,25,50,75$ e $100 \%$ de material reciclado incorporado a resina virgem nas temperaturas de 190,210 e $230{ }^{\circ} \mathrm{C}$. Observa-se que a resina $100 \%$ reciclada é a mais facilmente deformada, atingindo os
Tabela 2. Resultados de recuperação da deformação $(\gamma \mathrm{R})$ para as amostras nas temperaturas de 190,210 e $230{ }^{\circ} \mathrm{C}$.

\begin{tabular}{lccc}
\hline & \multicolumn{3}{c}{ Recuperação da deformação (\%) } \\
\cline { 2 - 4 } & $\mathbf{1 9 0}{ }^{\circ} \mathbf{C}$ & $\mathbf{2 1 0}{ }^{\circ} \mathbf{C}$ & $\mathbf{2 3 0}{ }^{\circ} \mathbf{C}$ \\
\hline $\mathrm{R}-0 \%$ & 23,9 & 19,4 & 16,4 \\
$\mathrm{R}-25 \%$ & 22,2 & 17,1 & 13,5 \\
$\mathrm{R}-50 \%$ & 20,8 & 15,4 & 13,3 \\
$\mathrm{R}-75 \%$ & 18,8 & 13,3 & 9,9 \\
$\mathrm{R}-100 \%$ & 16,3 & 11,7 & 8,8 \\
\hline
\end{tabular}

maiores valores de deformação, enquanto que a resina virgem é a menos deformável. Novamente este comportamento pode ser atribuído a menor quantidade de emaranhamentos (menor massa molar) existente na resina reciclada.

A recuperação da deformação ou recuperação elástica $\left(\gamma_{R}\right)$, apresentados na Tabela 2 em porcentagem, podem ser calculados por meio da Equação $3^{[13]}$, onde $\gamma_{i}$ é a deformação inicial após a retirada da tensão e $\gamma_{\mathrm{f}}$ é a deformação final após o tempo de 800 segundos:

$$
\gamma_{R}=\frac{\gamma_{i}-\gamma_{R}}{\gamma_{i}} .100
$$

Quanto maior a recuperação elástica, mais elástico (maior armazenamento de energia) é o material.

Pode se observar que a resina virgem é a mais elástica das composições, como era de se esperar, já que possui maior densidade de emaranhamentos, enquanto que a resina $100 \%$ reciclada é a menos elástica das formulações. Observa-se nas três temperaturas que a incorporação de material reciclado à resina virgem promoveu uma redução na recuperação da deformação, indicando portanto um menor reemaranhamento. Como a massa molar está diretamente relacionada ao emaranhamento, verifica-se que tal comportamento é decorrente das resinas, com maior porcentagem de material reciclado, apresentarem uma menor massa molar e, portanto menor reemaranhamento.

\section{Regime dinâmico}

$\mathrm{Na}$ reometria de placas paralelas, a medida das propriedades reológicas é realizada a partir da imposição de um fluxo de arraste, no caso a rotação de uma placa superior com uma determinada velocidade angular. Embora este tipo de reômetro seja utilizado para medir baixas taxas de cisalhamento $\left(<100 \mathrm{~s}^{-1}\right)$, ele pode fornecer importantes informações reológicas correlacionadas com a estrutura molecular do polímero. Com o intuito de verificar alterações na massa molar das amostras, determinou-se G' $(\omega)$ e G'” $(\omega)$ em função da frequiência.

A Tabela 3 apresenta os valores do ponto onde $G^{\prime}=G^{\prime}$ para as formulações estudadas.

Observa-se que a medida que se adiciona material reciclado à resina virgem, o valor da freqüência de cruzamento aumenta indicando uma redução da massa molar, enquanto que o valor de $\mathrm{G}^{\prime}=\mathrm{G}$ " diminui, indicando um aumento da distribuição de massa molar, como mostrado 
Tabela 3. Ponto de cruzamento, $\mathrm{G}^{\prime}=\mathrm{G}^{\prime}$, para as formulações.

\begin{tabular}{lcc}
\hline & $\omega(\mathbf{r a d})$ & $\left.\mathbf{G}^{\prime}=\mathbf{G}^{\prime} \boldsymbol{( P a}\right)$ \\
\hline $\mathrm{R}-0 \%$ & 2,71 & $4,4 \times 10^{4}$ \\
$\mathrm{R}-25 \%$ & 3,08 & $3,99 \times 10^{4}$ \\
$\mathrm{R}-50 \%$ & 3,58 & $3,62 \times 10^{4}$ \\
$\mathrm{R}-75 \%$ & 4,68 & $3,51 \times 10^{4}$ \\
$\mathrm{R}-100 \%$ & 6,67 & $3,38 \times 10^{4}$ \\
\hline
\end{tabular}

na Figura 1. Estes resultados estão em concordância com os resultados apresentados: o material reciclado apresenta-se com massa molar menor quando comparado com a resina virgem utilizada, mas com distribuição de massa molar maior.

\section{Reometria capilar}

A Figura 7 apresenta os resultados, corrigidos pela correção de Rabinowitsch, de reometria capilar na temperatura de 190,210 e $230{ }^{\circ} \mathrm{C}$ para as amostras contendo $0,25,50,75$ e $100 \%$ de material reciclado incorporado a resina virgem.

Medidas de reometria capilar são bastante úteis para a avaliação do material durante o processamento, já que são obtidas em taxas de cisalhamento de médias a elevadas similares às de processos. Os resultados obtidos de reometria capilar, apresentados na Figura 7, indicaram que com o aumento de temperatura ocorre uma ligeira redução na viscosidade. Também pode-se observar uma redução gradual nos valores de viscosidade com a incorporação de material reciclado à resina virgem. Observa-se que em taxas mais elevadas (aproximadamente $1000 \mathrm{~s}^{-1}$ ), os valores de viscosidade permanecem praticamente os mesmos.

A Tabela 4 apresenta os resultados de índice de potência (n) obtidos por meio dos ensaios de reometria capilar, para as amostras descritas anteriormente, nas temperaturas de 190,210 e $230{ }^{\circ} \mathrm{C}$. O valor de n é uma medida da pseudoplasticidade do polímero, que é consequiência do efeito em conjunto do desemaranhamento, orientação das macromoléculas e geração de temperatura por cisalhamento. Quanto mais próximo de zero, mais pseudoplástico é o material; ou seja, qualquer pequena variação na taxa de cisalhamento (proporcional à velocidade de processo) acarretará grandes variações na viscosidade do material (e conseqüentemente na vazão e queda de pressão do processo). Por outro lado quanto mais próximo de 1 menos pseu-

Tabela 4. Valores de índice de potência para as amostras R-0\%, R-25\%, $\mathrm{R}-50 \%, \mathrm{R}-75 \%$ e R-100\%, nas temperaturas de 190,210 e $230{ }^{\circ} \mathrm{C}$.

\begin{tabular}{lccc}
\hline & \multicolumn{3}{c}{ Índice de potência } \\
\cline { 2 - 4 } & $\mathbf{1 9 0}{ }^{\circ} \mathbf{C}$ & $\mathbf{2 1 0}{ }^{\circ} \mathbf{C}$ & $\mathbf{2 3 0}^{\circ} \mathbf{C}$ \\
\hline R-0\% & 0,25 & 0,25 & 0,27 \\
R-25\% & 0,29 & 0,26 & 0,29 \\
R-50\% & 0,28 & 0,29 & 0,32 \\
R-75\% & 0,31 & 0,32 & 0,32 \\
R-100\% & 0,34 & 0,34 & 0,38 \\
\hline
\end{tabular}

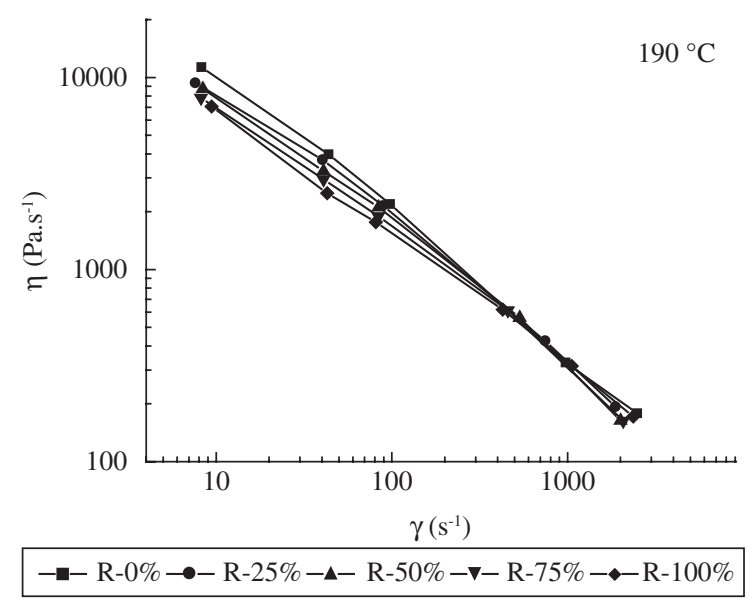

(a)

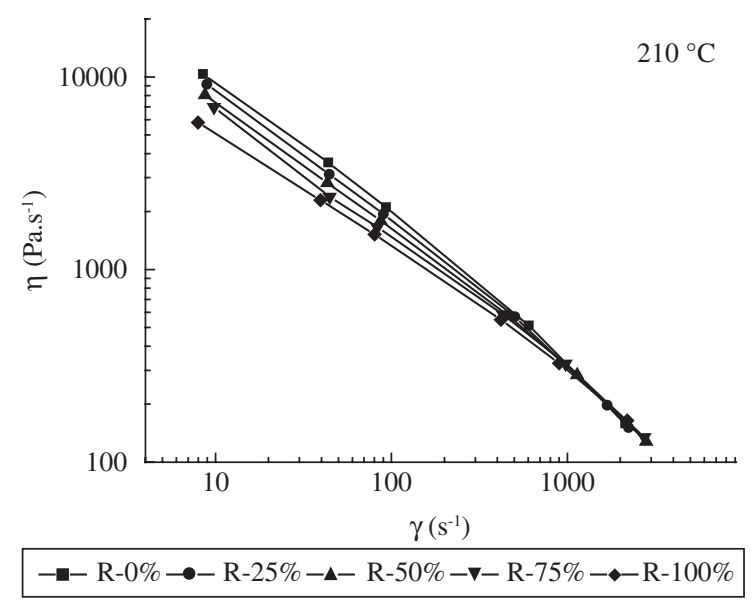

(b)

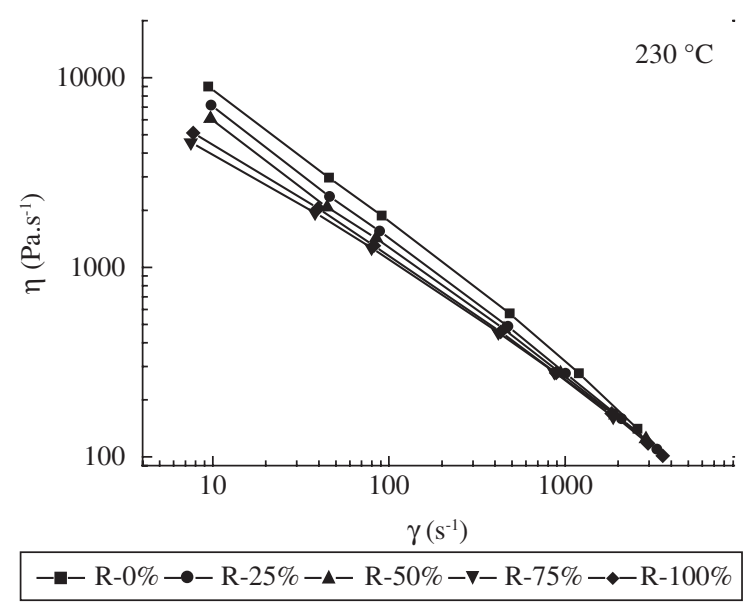

(c)

Figura 7. Viscosidade em função da taxa de cisalhamento para as formulações R- $0 \%$, R-25\%, R-50\%, R-75\% e R-100\% na temperatura de a) $190{ }^{\circ} \mathrm{C}$; b) $210^{\circ} \mathrm{C}$; e c) $230{ }^{\circ} \mathrm{C}$.

doplástico é o material tendendo para um comportamento Newtoniano.

Os resultados apresentados sugerem que com o aumento da incorporação de material reciclado à resina virgem 
ocorre uma tendência a aumentar o índice de potência e diminuir a pseudoplasticidade. Ou seja, a adição de material reciclado torna a composição menos pseudoplástica, e portanto com menor influência da taxa de cisalhamento na sua viscosidade.

\section{Conclusão}

Dos resultados obtidos, pode-se concluir que a incorporação de material reciclado, proveniente de resíduos pós-consumo, à resina virgem promove uma redução na massa molar das blendas em questão e um aumento na distribuição desta massa molar. Ainda, os resultados de medidas transiente indicaram que o polímero reciclado apresenta menor acúmulo de tensões e é mais facilmente deformado. Os resultados em regime dinâmico mostraram-se extremamente sensíveis na avaliação da massa molar e da sua distribuição, e confirmaram que o material reciclado apresenta redução de massa molar bem como aumento na sua distribuição. Finalmente, observou-se que as blendas com material reciclado são menos pseudoplásticas que a resina virgem.

\section{Referências Bibliográficas}

1. Mancini, S. D. \& Zanin, M. - Progress in Rubber, Plastic and Recycling Technology, 20, p. 117-132, 2004.

2. Ehring, R. J. - "Plastics recycling", products and processes, New York : Hanser Publishers, 1992. 289p.

3. Kelen, T. - "Polymer degradation". London : Van Nostrand Reinhold, 1983. 209p.

4. Calderoni, S. - "Os bilhoes perdidos no lixo", Humanitas Publicações, 1999, 346p.
5. Osswald, T. \& Menges, G. - "Materials Science of Polymers for Engineers", New York : Hanser Publishers, 1995. 475 p.

6. Macossko, C. W. - "Rheology Principles, Measurements, and Applications", New York: VCH Publishers, 1994. $549 \mathrm{p}$.

7. Ferry, J. D. - "Viscoelastic Properties of Polymers", Second Edition, New York : Jonh Wiley \& Sons, 1970. $671 \mathrm{p}$.

8. Yoo, H. J. - Advances in Polymer Technology, 13, p.201-205, 1994.

9. Memon, N. A. \& Muller, R. - Journal Polymer Science: Part B: Polymer Physics, 36, p.2623-2634, 1998.

10. Manrich, S.; Herrera, J. C.; Rosalini, A. C. \& Acconi C. - "Lavadora e secadora para materiais poliméricos". Patente UM 7901580, 1999.

11. Bretas, R. E. S. \& D’Avila, M. A. - "Reologia de polímeros fundidos", 2a Edição, São Carlos : Edufscar, 2005. $257 \mathrm{p}$.

12. Cruz, S. A. \& Zanin, M. - Polymer Degradation and Stability, 80, p. 31-37, 2003.

13. Scuracchio, C. H; Bretas, R. E. S. - "Journal of Elastomers and Plastics", 36, p.47-75, 2004.

Enviado: 18/09/07

Reenviado: 15/11/07

Aceito: $21 / 11 / 07$ 